\title{
Power Management for Hybrid Vehicles by Battery and Supercapacitors (Application using multi-boost and full bridge converter)
}

\author{
Priya Kumari, Ashutosh Pandey, D. Sivakumar, V.N. Ganesh
}

\begin{abstract}
During past years, hybrid energy and its storage system has become solution of non-stop supply, reliable, eco-friendly energy supply to power electronic (PE) devices. Supply given to power electronic devices by storage system can give required energy and enhance its characteristics for specific task. In today's generation requirement of energy at a time can be filled by renewable sources of energy by combining it properly with energy storage system. This paper is focused on use of supercapacitor and Battery Association Methodology for hybrid vehicle system. So, the set of Motor drive and generator is set to control gear system of vehicle, and the energy is delivered by a set of two capacitor, each having 108 module produces maximum of 270 volt to complete the requirement. The produced voltage can also enhanced by using multi-bridge and multi-boost converter to good power management. The output voltage of converter topology is directly connected to rotor of DC motor drive and generator set wheel, so it is easier to achieve desired speed of vehicle. In this paper multi-bridge and multi-boost converter is simulated and studies with the application of supercapacitor in battery energy storage system
\end{abstract}

\section{INTRODUCTION}

Lately, the pollution and increment in the price of fossil fuels has become an important issue worldwide. The manufacturers of vehicles such as car has reacted to this pollution issue by advertising and bringing forward electric vehicles. But still certain issues such as the weight of battery and cost was not resolved. The battery must deliver energy \& maximum power throughout temporary conditions. Thus these are the intense condition for the batteries.

To minimize the intense condition batteries with good power management and super-capacitors is a reliable solution to these issue. We know that capacitors connected to circuits are used to store energy while current is flowing through the circuit, so that at time of sudden shut down or power failure the circuit does not get effected. But Supercapacitors stores maximum power and supply peak power to the hybrid

vehicles during the transient-state.

Since batteries are having high energy density while

Revised Version Manuscript Received on 10, September 2019.

PriyaKumari,UG Student, Department of Electrical and Electronics Engineering, SRM Institute of Science and Technology, Chennai, Tamilnadu, India.

AshutoshPandey, UG Student, Department of Electrical and Electronics Engineering, SRM Institute of Science and Technology, Chennai, Tamilnadu, India.

D. Sivakumar,Assistant Professor, Department of Electrical and Electronics Engineering, SRM Institute of Science and Technology, Chennai, Tamilnadu, India.

V.N. Ganesh, Assistant Professor, Department of Electrical and Electronics Engineering, SRM Institute of Science and Technology, Chennai, Tamilnadu, India. supercapacitor having higher power density. Thus a hybrid vehicle which consists of battery and supercapacitor as energy storage system will have high power density and higher energy density. Supercapacitor can be used to store energy in few second during the process of regenerative braking in hybrid vehicle system. The main drawback of supercapacitor is that, it having high rate of self-discharging. Which make it necessary to use along with battery in hybrid vehicle system.

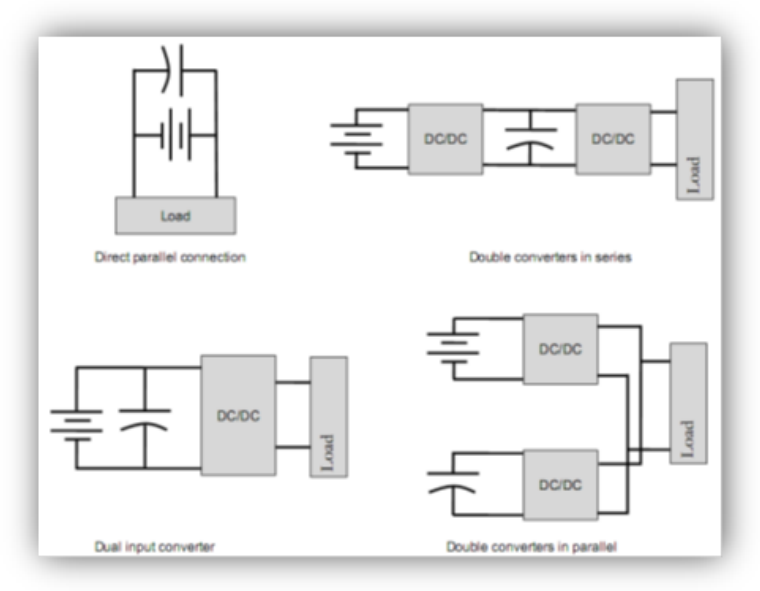

Fig:1 Different configuration of battery/supercapacitor system

Thus this helps the batteries to reduce their mass and increase the life-span of the batteries. Multi-boost converter and multi full-bridge converter are used as they give high power and have good power management. The two topologies proposed are presented below:

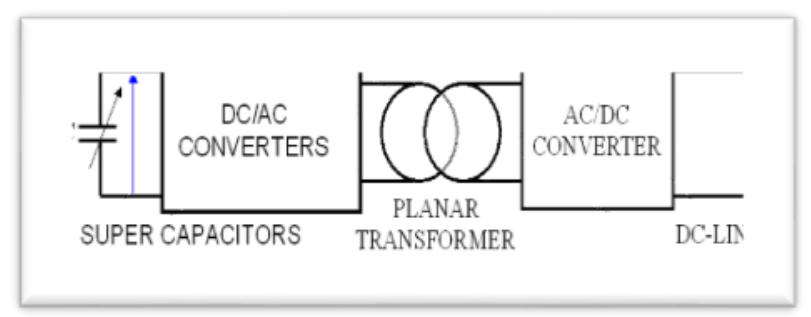

Fig: 2(a) 


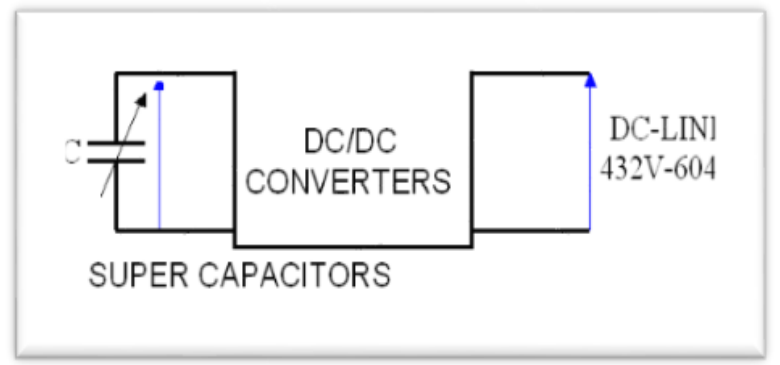

Fig: 2(b)

Fig:2 Converter topology for ECCE hybrid vehicle System

\section{MODELLING OF DC/DC CONVERTERS AND ITS CONFIGURATION}

Multi-full bridge and Multi-boost converter modelling:

Fig. 3(a) depicts DC/DC multi-boost converter configuration. The below given equation (1) represents a general model of this configuration.

Here (a1) and (n) is a duty cycle and parallel converter numeral.

Ln d/dt (Iscn) $=$ V_scn $-\alpha 1$. Vbus

IL. V_bus1= P_bus $1+P \_$bus $2+\ldots+P$ _busn

$\lambda \mathrm{D} / \mathrm{dt}(\mathrm{Ibat})=\mathrm{V} \_$bat $-\mathrm{V} \_$bus 1

$\mathrm{Ich}=\mathrm{Ibat}+\mathrm{k}$. IL

The potential drop across $\operatorname{Ln}$ and $\lambda$ inductor are given by the eq. (2)

$\mathrm{VLn}=\mathrm{d} / \mathrm{dt}$ (Iscn)

$\mathrm{V} \lambda=\lambda \mathrm{D} / \mathrm{dt}(\mathrm{I}$ bat $)$

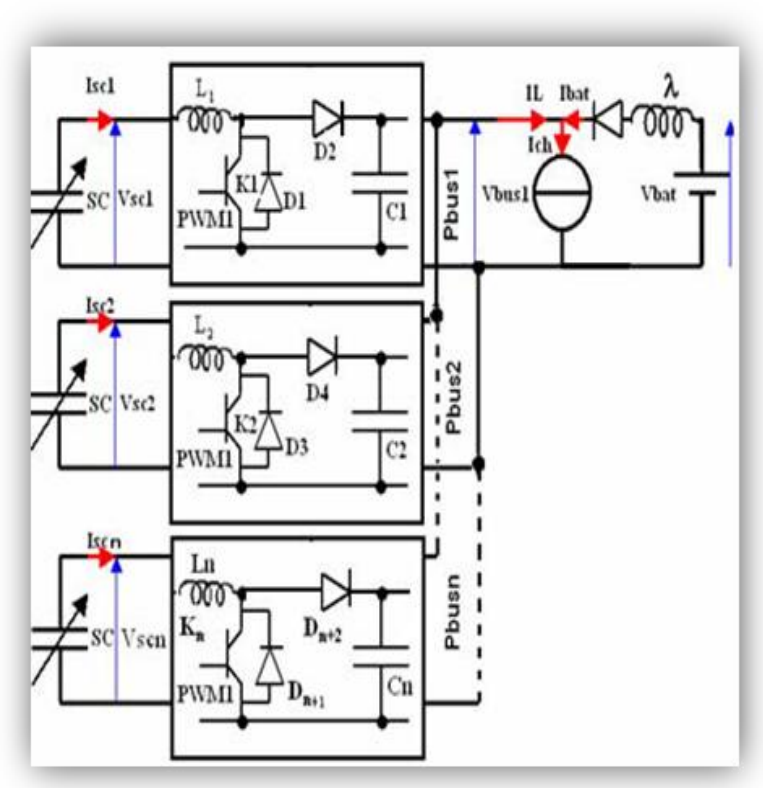

Fig:3(a)

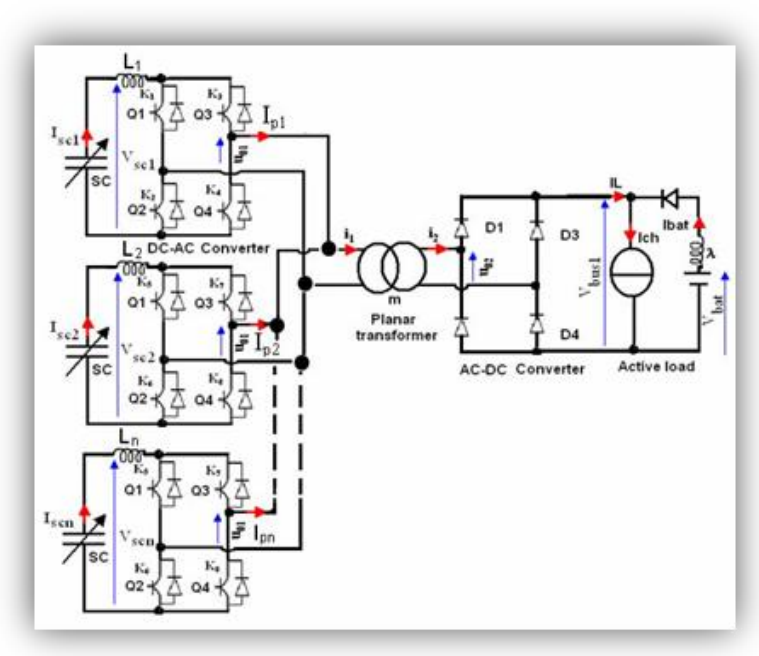

Fig: 3(b)

Fig: 3(a)Multi-b0ost c0nverter top0logy3(b) Multi-fill bridge c0nverter top0logy

The converter design presents non-linear characteristics due to cross between Vbus 1 parameter and $\alpha 1$ control variable. The Vscn, V_sc1, V_sc2, V_bus1, I_ch and V can interrupt the controller system. Therefore these values must be measured and controlled for reliable and efficient operation

The Multi-b0ost converter (5) configuration control law which can be depicted from boost converter topology given by alpha_1 duty cycle (3); where $\mathrm{Np}=\operatorname{maximum~(n).~}$

$$
\begin{aligned}
& \alpha_{1} \\
& =1 \\
& -\frac{1}{N_{P}} \cdot \frac{\left(V_{s c 1}+V_{s c 2}+\cdots+V_{s c n}\right)-\left(V_{L 1}+V_{L 2}+\cdots+V_{L n}\right)}{V_{b}-V_{\lambda}}
\end{aligned}
$$

Control plan of multi-b0ost convert is given in fig.4 (a). From the diagram we can analysed that supercapacitor is discharge with variable current. This control methodology incorporates the super_capacitors and batteries current control circles. PWM_1 signal guarantees the multi-b0ost converter control amid super- capacitor unit's discharge. To reduce the complexity the super-capacitors current orientations likely, the multi-b0ost converter efficiency $(\eta)$ is specified at $85 \%$.

Thus the specified voltage is estimated with two triangular carrier signals of amplitude $\mathrm{V}=1 \mathrm{~V}$ with a switching recurrence of $20 \mathrm{kHz}$. The inverter control approach is presented in Fig. 4(b).

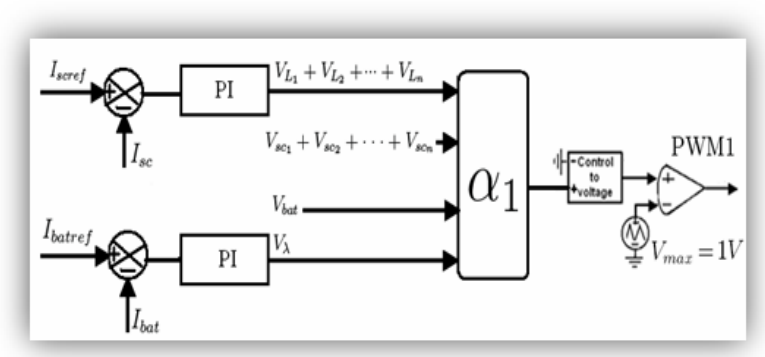

Fig: 4(a) 


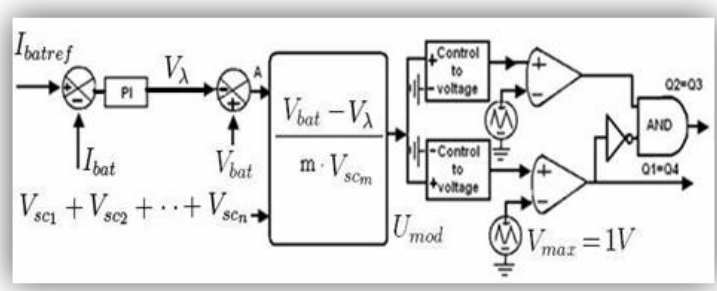

Fig: 4(b)

Fig.4(a) Multi-b0ost converter control strategy, 4(b) full bridge converter control strategy

\section{EXPERIMENTAL DESIGN AND SIMULATION RESULT}

Here experimental and design setup for the simulation circuits are presented, along with their results

Multi-b0ost converter simulation and result:

The condition to carry out boost converter experiment, When capacitor discharges, the reference current of batteries are fixed at 13A. So that supercapacitor can provide power to hybrid vehicle system during temporary conditions.

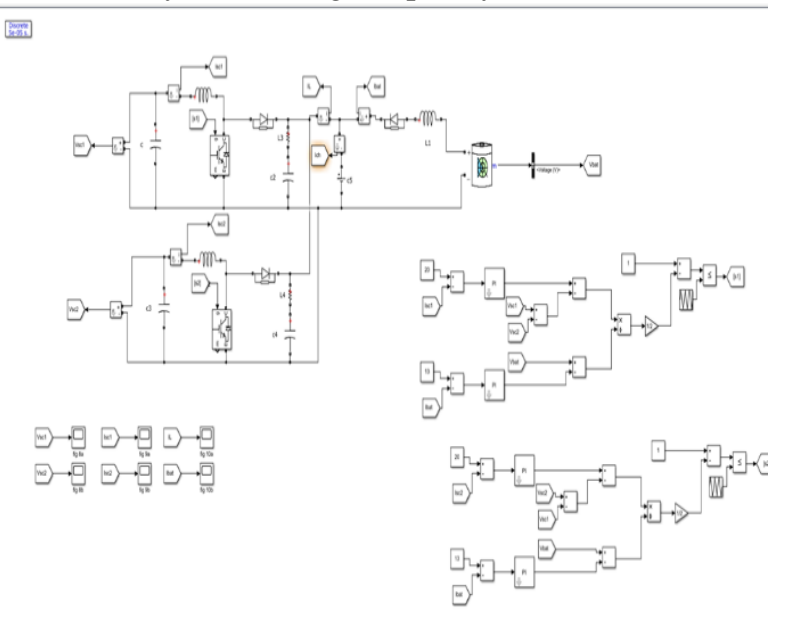

Fig: 5 Multi_boost converter circuit

For these trials, the hybrid vehicle demand (Ich) was set at 53_A. The investigational and replication outcomes are associated in Fig.6(a) and Fig.6(b).Short circuit current (Isc1\&Isc2) investigational currents are not same in Fig.7(a), Fig.7(b) since the super capacit0rs distribution \& the power automated-circuits (b0ost converters) dissimilarity.

The $1^{\text {ST }} \&$ the $2^{\mathrm{ND}}$ one guarantees also $50 \%$ of the DC-link current (IL). In other words the two super capacitors units guarantee a (IL) current of 40amp to hybrid automobile as shown in Fig.8(a), and 13amp only is provided by the batteries Fig.8 (b).

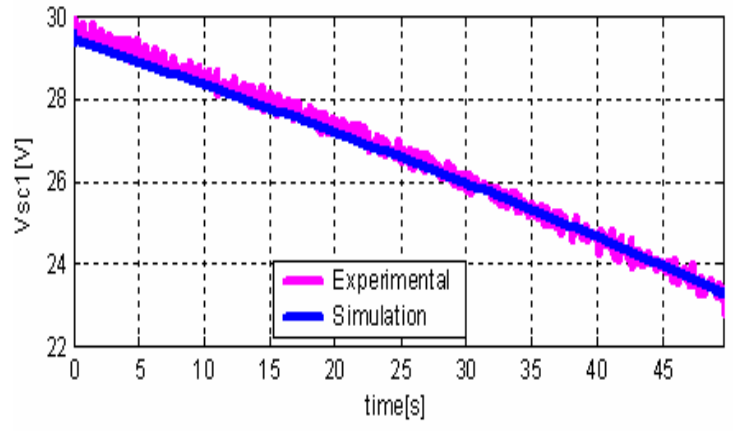

Fig: 6 (a) $1^{\text {st }}$ unit voltage

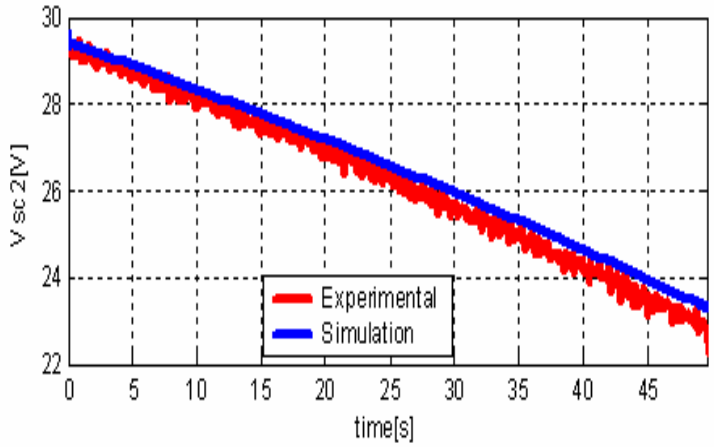

Fig: 6(b) $2^{\text {nd }}$ unit voltage

Figure.6 Super-capacitor unit investigational and simulation voltage outcomes

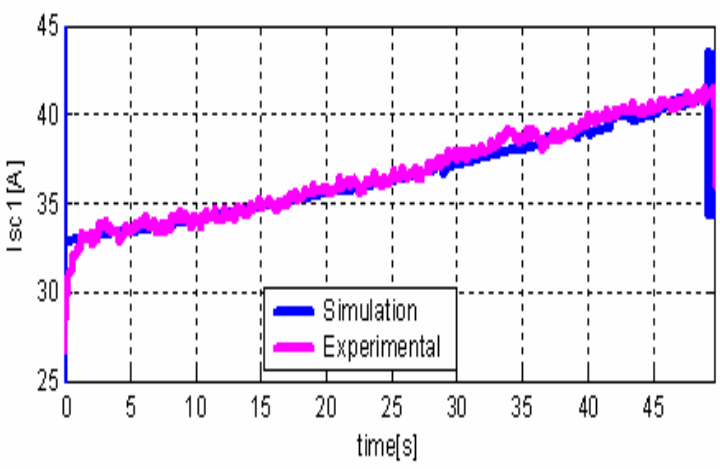

Fig: 7(a) $1^{\text {st }}$ unit current

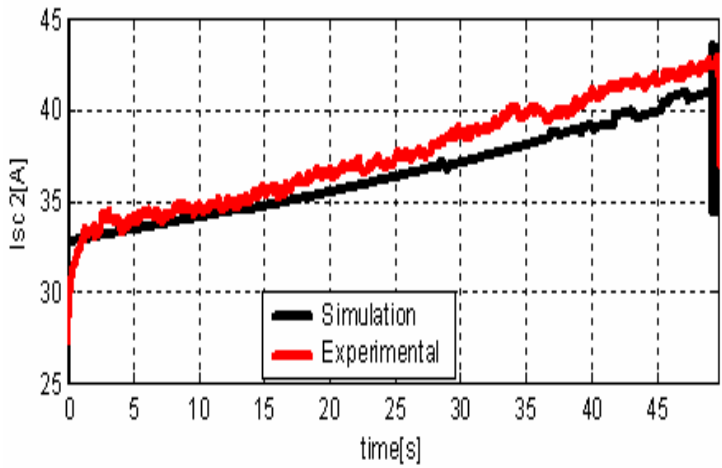

Fig: 7(b) $2^{\text {nd }}$ unit current

Figure:7 Super-capacitor unit experiment and current simulation outcome

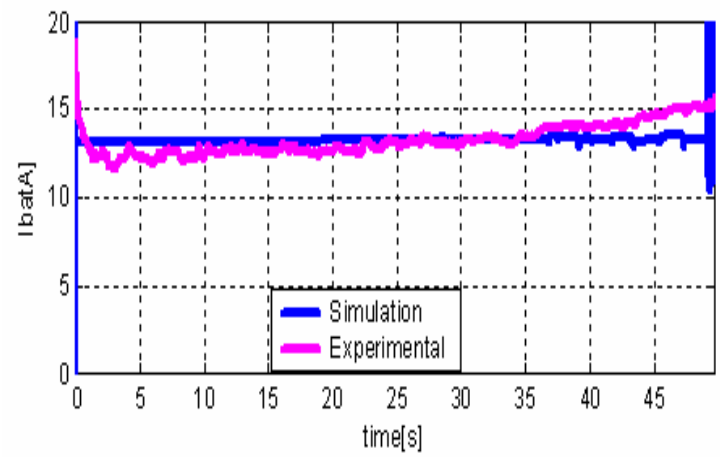

Fig: 8 a) Multi-b0ost output current

Published By:

Blue Eyes Intelligence Engineering

\& Sciences Publication 

bridge converter)

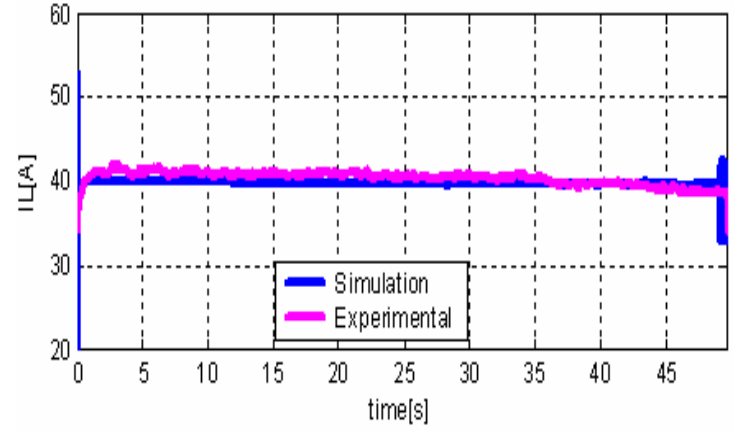

Fig: 8(b) Battery current experiment outcome

\section{FULL BRIDGE CONVERTER EXPERIMENTAL DESIGN AND SIMULATION}

Here simulation is done for $\mathrm{Np}=2$. The extreme and least powers of super-capacitor units are correspondingly secured at 270volt and 135volt. The current amplitudes are also equal and the voltage of supercapacitors are also same. The significant power of the temporary conditions is guaranteed via super capacitors units (IL). Simulation for the same is obtained.

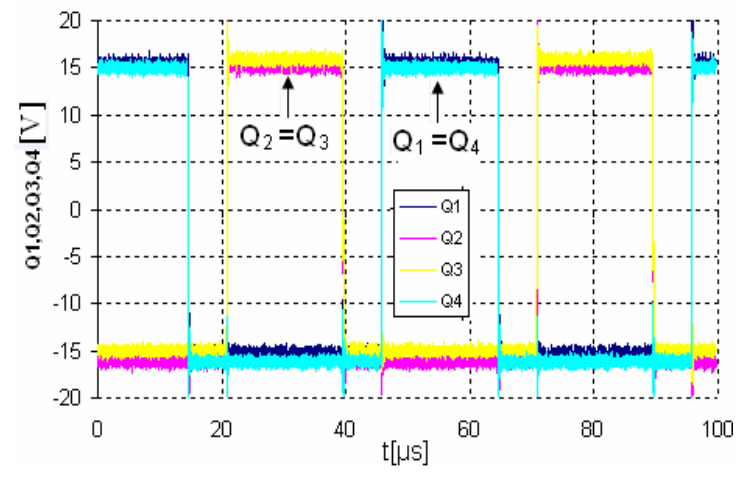

Fig: 9(a) Full-Bridge control signal

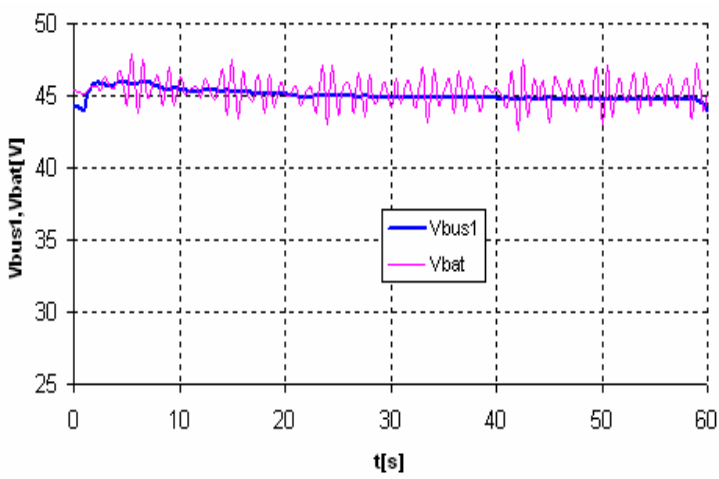

Fig:9(b) Battery \& DC- Link experimental voltages

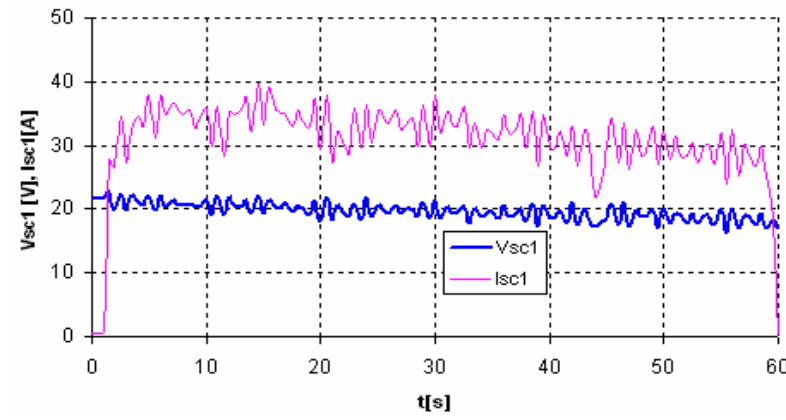

Fig: 10 Super capacitor unit voltage and current

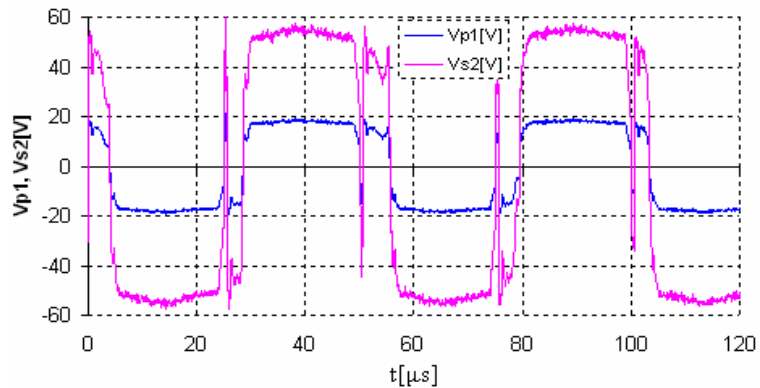

Fig: 11(a) Transformer $o / p$ and i/p voltage

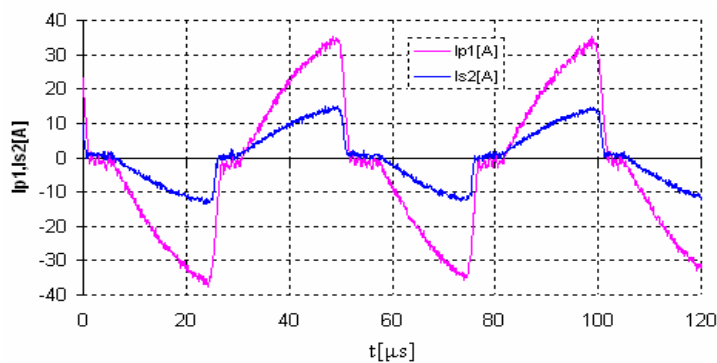

Fig: 11(b) Transformer I/p and o/p current

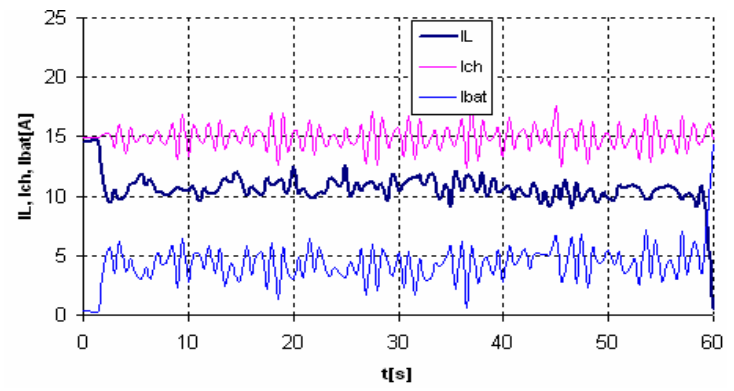

Fig: 12 DC-link and active load experimental currents

\section{CIRCUIT DIAGRAM FOR THE MULTI FULL-BRIDGE CONVERTER}

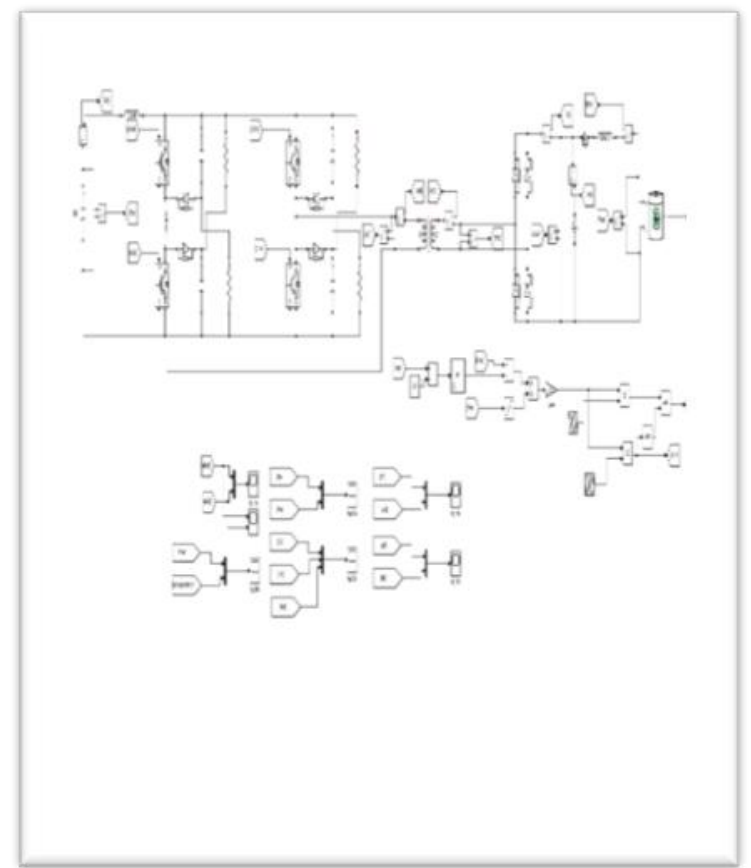

Figure.13 Multi-full bridge Converter

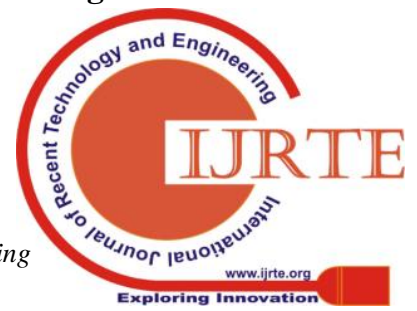


Multi full-bridge converter is multiple input dc-dc converter. So it can take input from different sources of energy which reduces the cost of system and achieve good power management. Circuit diagram of Multi full-bridge converter is shown in figure.13. Its consists of power mosfet, diode, isolation transformer and battery storage system

\section{PROPOSAL OF PLANETARY GEAR SYSTEM TOPOLOGY AND SIMULATION RESULT}

It consists of the electrical subsystem, electrical management subsystem, the internal combustion engine, planetary gear subsystem. Further the circuit diagrams of electrical management system, electrical subsystem and planetary system is presented.

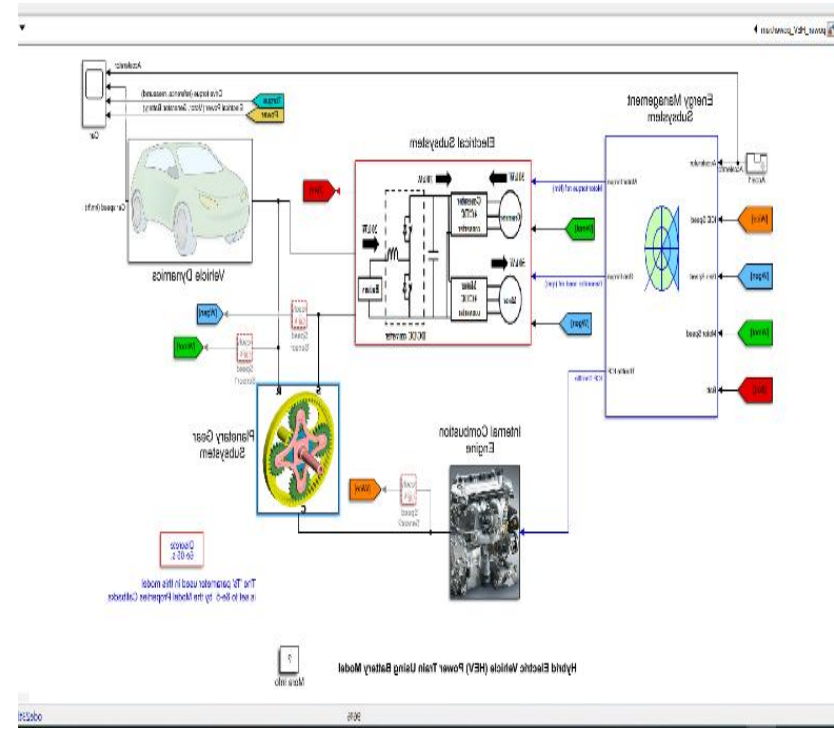

Fig: 14 Hybrid Vehicle Power Train Using Battery Model

The above design in fig: 14 is a hybrid electric vehicle power train using battery model. This basically is the complete design of the presented system. The planetary gear system shown in fig: 15 consists of electric motor of 500 Volt DC and an inner permanent magnet synchronous machine of 50 kilowatts. The motor consists of 8 poles. The generator associated with the system has 2 pole, 500 volt dc and 50 kilowatts rating respectively. The simulation result for the same is shown in figures below. The electrical subsystem shown in fig: 16 consists of a battery, a dc/dc converter a motor drive of 50kilowatts, a generator drive of 30 kilowatts and PMSM

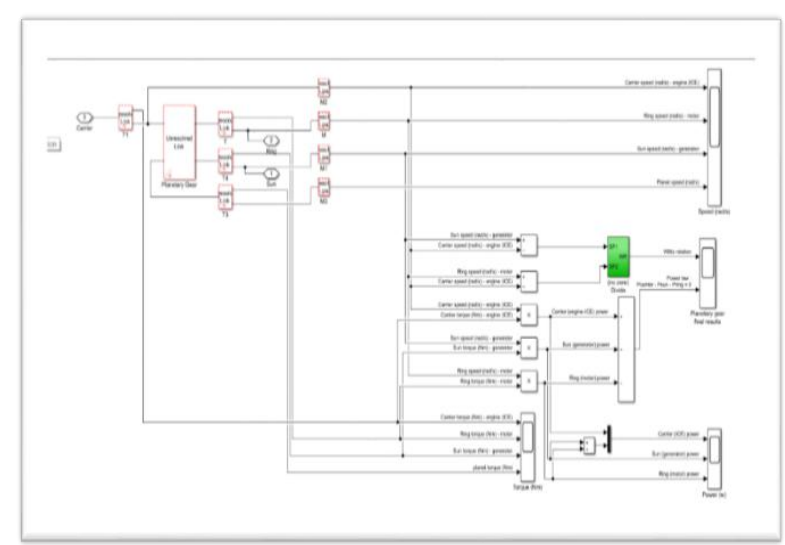

Fig: 15 Planetary gear system

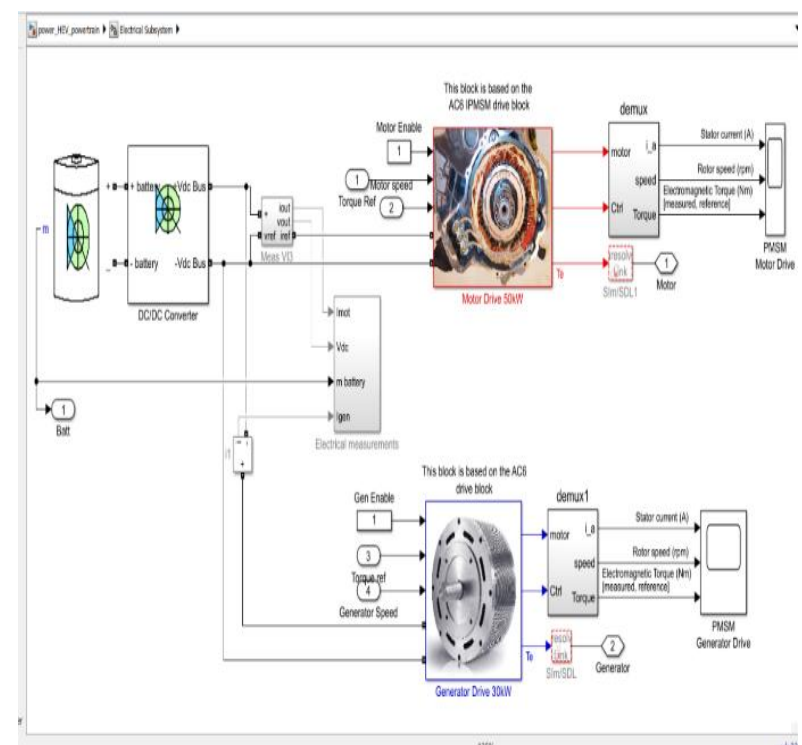

Fig: 16. Electrical subsystem

The electrical management system is shown below. It is the main system to which the electrical subsystem and planetary gear system is connected. The design of the electrical management unit is shown below in fig: 17 below in fig: 17

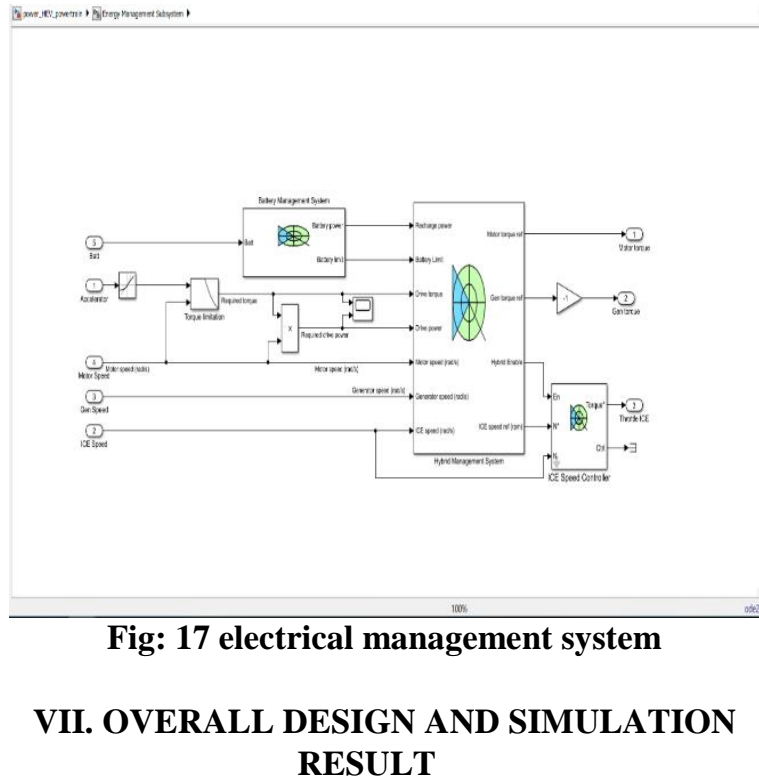

The given circuit design is the overall design of the presented paper.

The circuit diagram is simulated and the results are presented below. 


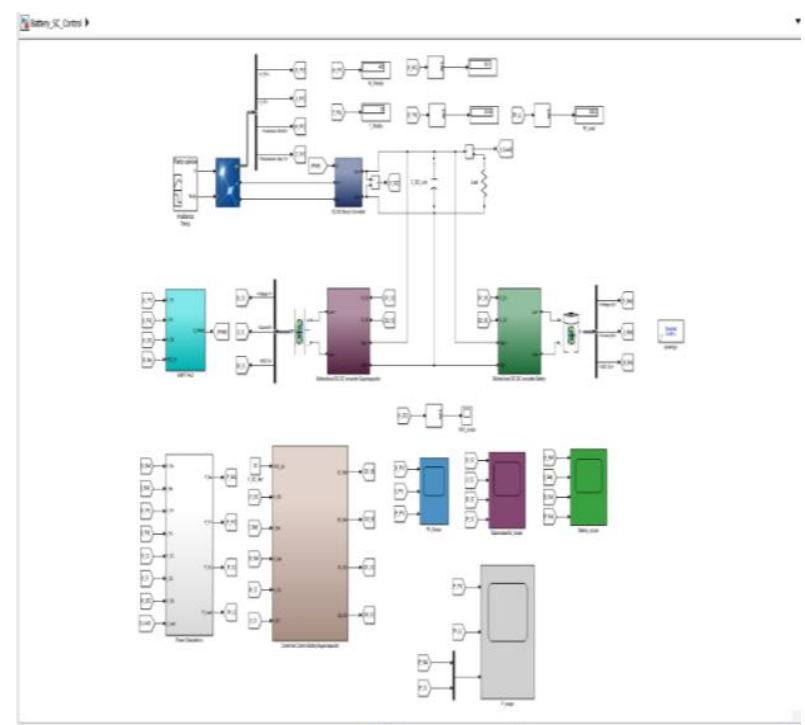

Fig: 18 Overall Design System

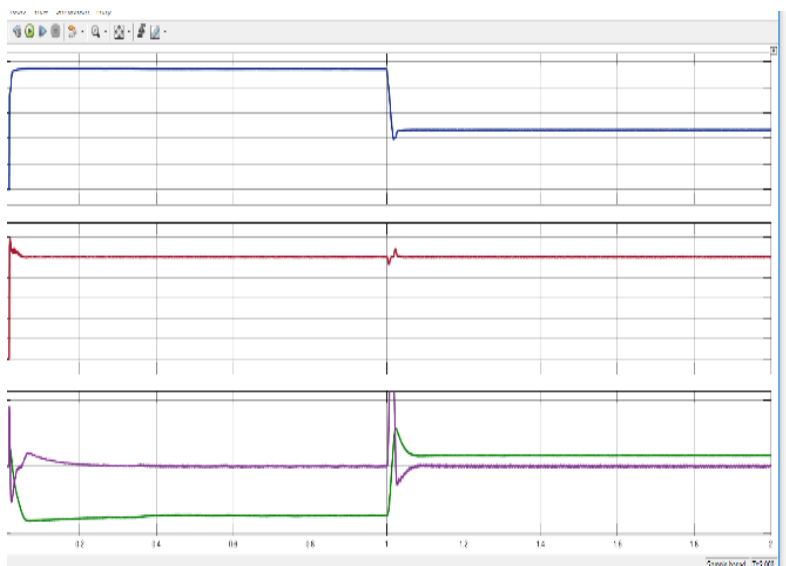

Fig:19. P_Scope output

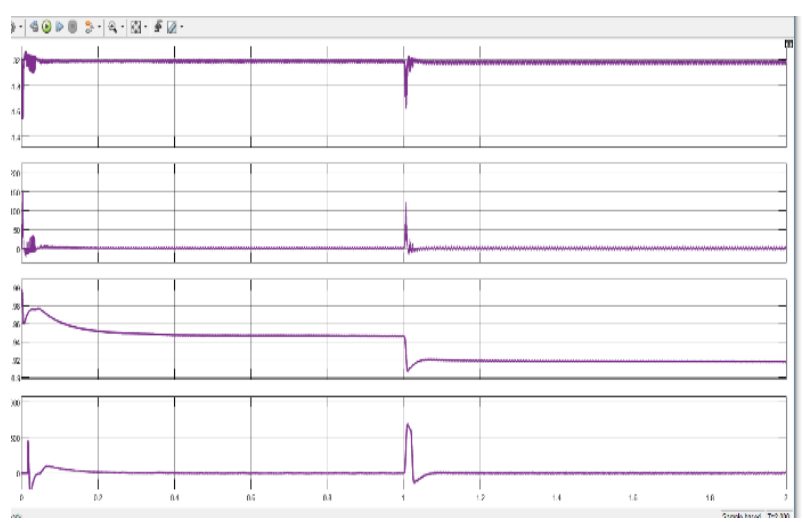

Fig:20. Supercapacitor output

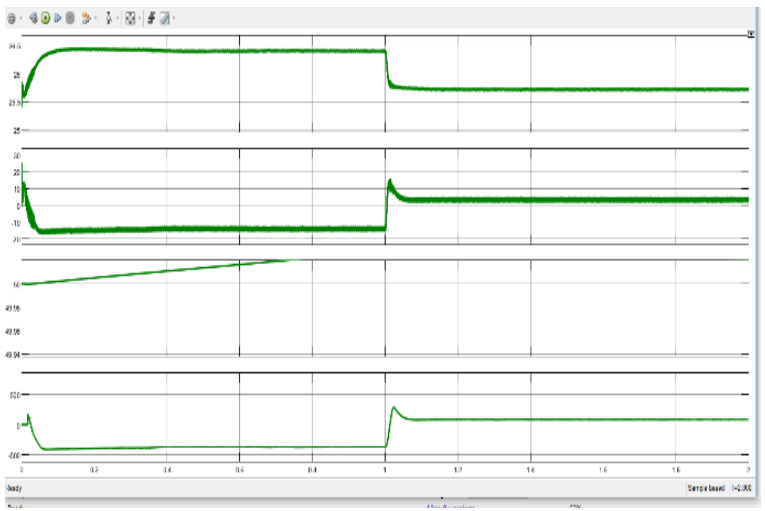

Fig:21. Battery output

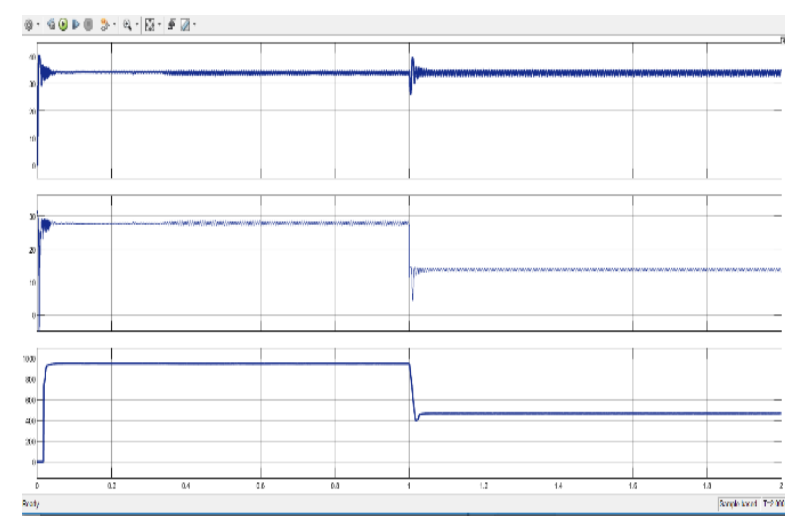

Fig:22. PV_Scope output

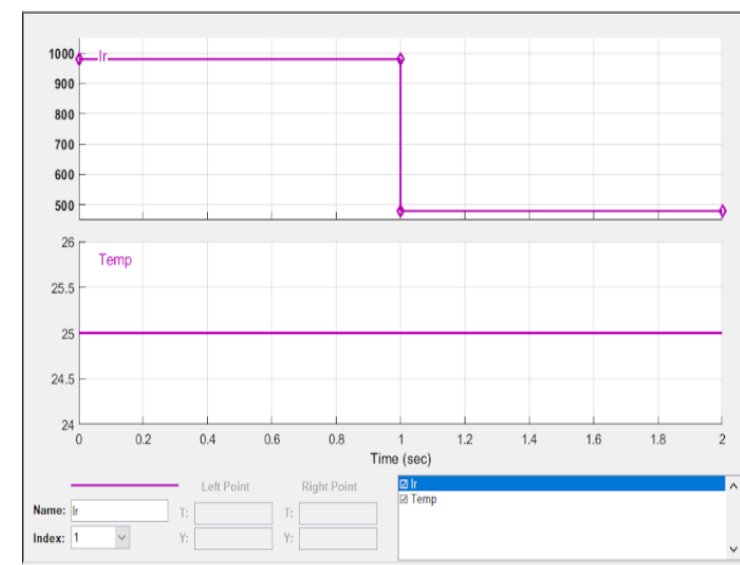

Fig.23 Battery SC control/ Irradiance Temperature

Fig.19 shows power management of vehicle, Fig.20 shows Battery output in form of voltage signal of vehicle, fig. 21 shows the voltage output of supercapacitor, fig 22 shows input voltage of pv cell, fig.23 shows the output of supercapacitor combined with battery and the irradiance temperature of SC

\section{CONCLUSION}

Thus in this presented paper we have done power management of hybrid vehicles using supercapacitor and battery. We have used supercapacitor because of its advantage of giving extreme voltage during temporary states. Due to its use the weight of batteries gets reduced and its lifespan increases. It also becomes more efficient and reliable. Multi-boost converter and multi full-bridge converter are used as they give high power and have good power management. The planetary gear system and its simulation is also presented.

Hence the paper has successfully presented its view about power management of hybrid vehicles using supercapacitor and battery.

\section{REFERENCES}

1. M.B. Camara, F. Gustin, H. Gualous, A. Berthon "Supercapacitors and battery power management for hybrid vehicle applications using multi boost and full bridge converters" ,2007 European Conference on Power Electronics and Applications, 2007

Published By:

Blue Eyes Intelligence Engineering

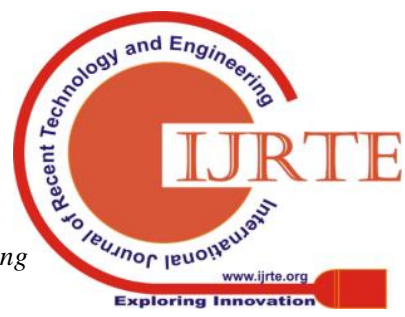


2. J.M Timmermans, P. Zadora, J. Cheng, Y. Van Mierlo, and $\mathrm{Ph}$. Lataire. Modelling and design of super capacitors as peak power unit for hybrid electric vehicles.

3. Allam, Essam M., and Sameh M. Metwalley. "Hybrid electric vehicle power train using battery model simulation in Simulink and its use for power management studies", International Journal of Electric and Hybrid Vehicles, 2012.

4. WenyuBai, Datong Qin, Yawen Wang, Teik C. Lim. "Dynamic characteristics of motor-gear system under load saltations and voltage transients", Mechanical Systems and Signal Processing, 2018

5. Huang jen Chiu, Hsiu Ming Li-Wei Lin, and Ming-Hsiang Tseng. A multiple- input dc/dc converter for renewable energy systems. ICIT2005, IEEE, 14-17 December, pages 1304-1308, 2005.

6. .M.B. Camara, H. Gualous, F. Gustin, and A. Berthon. Control strategy of hybrid sources for transport applications using supercapacitors and batteries. IPEMC2006, 13-16 August, Shanghai, P.R.CHINA, $1: 1-5,2006$.

7. L. Solero, A. Lidozzi, and J.A. Pomilo. Design of multiple-input power converter for hybrid vehicles. IEEE transactions on power electronics, 20, Issue 5, 2005.

8. Xin KONG and A. KHA. Analysis and implementation of a high efficiency, interleaved current-fed full bridge converter for fuel cell system. IEEE, 28-01 Nov, 1:474-479, 2005.

9. M.B. Camara, F. Gustin, H. Gualous and A. Berthon. Studies and realization of the buck-boost and full bridge converters with multi sources system for the hybrid vehicle applications. Second European Symposium on Super capacitors and Applications, ESSCAP2006, Lausanne, Switzerland, 2-3 November, 2006.

10. Huang-Jen Chiu, Hsiu-Ming, Li-Wei Lin, Ming-Hsiang Tseng. A Multiple-Input DC/DC Converter for Renewable Energy Systems, Industrial Technology, ICIT2005, IEEE international Conference, 14-17 December 2005, Pages: 1304-1308

11. LOUNIS Zohra. APPOTS DES TECHNIQUES DE CABLAGES LAMINAIRES DANS UN ONDULEUR A IGBT DE MOYENNE PUISSANCE. PhD thesis, Institut National Polytechnique de Lorraine, 2000.

12. Seong-JeubJeon, Gyu-Hyeong Cho. A Zero-Voltage and Zero-Current Switching Full Bridge DC-DC Converter with Transformer Isolation, IEEE Transactions on power Electronics, Vol.16, No.5, September 2001, Pages: 573-580 